\title{
The role of neurotrophic factors in nerve regeneration
}

\author{
Tessa Gordon, Ph.D. \\ Centre for Neuroscience, Division of Physical Medicine and Rehabilitation, Faculty of Medicine and \\ Dentistry, University of Alberta, Edmonton, Alberta, Canada
}

\begin{abstract}
This review considers the 2 sources of neurotrophic factors in the peripheral nervous system (PNS), the neurons and the nonneuronal cells in the denervated distal nerve stumps, and their role in axon regeneration. Morphological assessment of regenerative success in response to administration of exogenous growth factors after nerve injury and repair has indicated a role of the endogenous neurotrophic factors from Schwann cells in the distal nerve stump. However, the increased number of axons may reflect more neurons regenerating their axons and/or increased numbers of axon sprouts from the same number of neurons. Using fluorescent dyes to count neurons that regenerated their axons across a suture site and into distal nerve stumps, brain-derived neurotrophic factor (BDNF) and glial cell-derived neurotrophic factor (GDNF) were found not to increase the number of neurons that regenerated their axons after immediate nerve repair. Nevertheless, the factors did reverse the deleterious effect of delayed nerve repair, indicating that the axons that regenerate into the distal nerve stump normally have access to sufficient levels of endogenous neurotrophic factors to sustain their regeneration, while neurons that do not have access to these factors require exogenous factors to sustain axon regeneration. Neurons upregulate neurotrophic factors after axotomy. The upregulation is normally slow, beginning after 7 days and occurring in association with a protracted period of axonal regeneration in which axons grow out from the proximal nerve stump across a suture site over a period of 1 month in rodents. This staggered axon regeneration across the suture site is accelerated by a 1-hour period of low-frequency electrical stimulation that simultaneously accelerates the expression of BDNF and its trkB receptor in the neurons. Elevation of the level of BDNF after 2 days to $>3$ times that found in unstimulated neurons was accompanied by elevation of the level of cAMP and followed by accelerated upregulation of growth-associated genes, tubulin, actin, and GAP-43 and downregulation of neurofilament protein. Elevation of cAMP levels via rolipram inhibition of phosphodiesterase 4 mimicked the effect of the low-frequency electrical stimulation. In conclusion, the enhanced upregulation of neurotrophic factors in the electrically stimulated axotomized neurons accelerates axon outgrowth into the distal nerve stumps where endogenous sources of growth factors in the Schwann cells support the regeneration of the axons toward the denervated targets. The findings provide strong support for endogenous neurotrophic factors of axotomized neurons and of denervated Schwann cells playing a critical role in supporting axon regeneration in the PNS. (DOI: 10.3171/FOC.2009.26.2.E3)
\end{abstract}

KEY WORDS $\bullet \quad$ axon regeneration $\bullet \quad$ cAMP $\bullet \quad$ electrical stimulation
neurotrophic factors $\quad \bullet \quad$ rolipram and accelerated axon regeneration

$\mathrm{S}$ INCE their discovery, putative roles of the neurotrophic factors have been extensively explored in the CNS and PNS. Localization of the factors and their receptors and their putative roles have been and are being investigated with a wide variety of techniques. The advent of molecular biological techniques, including the propagation of transgenic mice with selective or generalized over- or underexpression or deletion, has been instrumental in demonstrating the vital and complex role that the neurotrophic factors play in differentiation and survival of neurons and glial cells during embryonic and

\footnotetext{
Abbreviations used in this paper: $\mathrm{BDNF}=$ brain-derived neurotrophic factor; cAMP = cyclic adenosine monophosphate; CNS = central nervous system; CTNF = ciliary neurotrophic factor; $\mathrm{GDNF}=$ glial cell-derived neurotrophic factor; $\mathrm{NGF}=$ nerve growth factor; $\mathrm{PKA}=$ protein kinase $\mathrm{A} ; \mathrm{PNS}=$ peripheral nervous system.
}

postnatal development of the CNS and PNS. In the adult nervous system, the role of the neurotrophic factors in neuronal survival and capacity for axon regeneration has also been the subject of considerable investigation both with respect to nerve injuries in the CNS and PNS and to neurological diseases that include Parkinson and Alzheimer diseases.

In the PNS, extensive in vitro analysis of the signaling of neurotrophic factors via trk and 775 receptors, GDNF via the GFR-a and ret receptors, and the CNTF-neuropoetic cytokines and their CNTF and gp130 receptors have elucidated intracellular signal transduction pathways downstream of the receptors; these pathways, which mediate differentiation, survival, and growth, are distinct and/or show considerable overlap. . $^{144,55,93,97}$ While there is a body of evidence that neurotrophic factors promote neuronal survival, ${ }^{14,97}$ analysis of the function of growth or 
T. Gordon
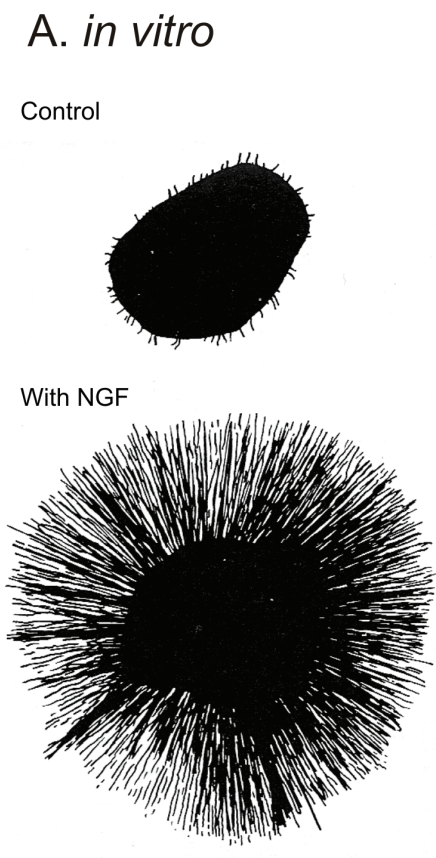

\section{B. in vivo}

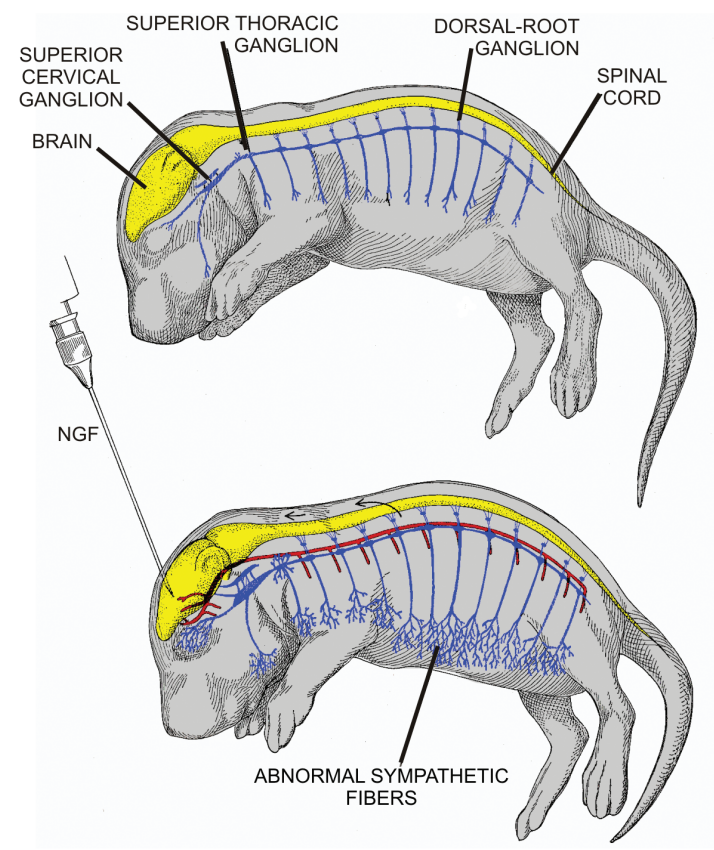

FIG. 1. Nerve growth factor (NGF) promotes neurite outgrowth in vitro and axon outgrowth in vivo. A: Micrographs of dorsal root ganglion neurons in vitro that were dissected from 8-day old chick embryos and placed in tissue culture medium in the absence and presence of nerve growth factor. Initially published in Nicholls, Martin and Wallace: From Neuron to Brain, ed 3. Reprinted with permission from Sinauer Associated, Inc. B: Illustration of the sympathetic nerve fibers in newborn rats that normally innervate peripheral tissues such as blood vessels and of the same fibers in newborn rats into which NGF is injected into the brain The injected NGF diffused from the injection site to the spinal cord and reached the adjacent sympathetic ganglia through the ventral and dorsal roots. NGF promoted abnormal and diffuse projection of these fibers in both the peripheral (nerves in blue) and central nervous systems (nerves in red). Adapted from reference 58 and reprinted with permission from Carol Donner.

neurotrophic factors, in contrast, opened a Pandora's box. An important example is that of the purified active agent of the mouse tumor sarcoma, which was termed nerve growth factor (NGF) on the basis of the original dramatic demonstrations of neurite outgrowth from isolated chick embryonic sympathetic nerve ganglion in vitro (Fig. 1A). ${ }^{58}$ This terminology was, in hindsight, unfortunate, because the functional name thereafter promoted a subsequent explosion of studies of the effects of this neurotrophic factor on nerve growth. The most striking and conclusive study was that of Levi-Montalcini herself, who demonstrated extensive axonal outgrowth in the CNS and PNS in vivo in response to exogenous NGF (Fig. 1B). Yet it is now recognized that elevations in the level of endogenous NGF and subsequent NGF-dependent rise in the level of BDNF also mediate inflammatory pain and asthma., ${ }^{720,77}$ Hence reference to "growth" in the names of the neurotrophic factors should be interpreted with care.

Yet, the evidence for exogenous neurotrophic factors promoting more axons in nerve stumps distal to crush and transection injuries, more axons within nerve grafts and conduits, and positive functional outcomes of axon regeneration from walking track analyses has been used, together with evidence of neurite outgrowth in vitro, to support the view that neurotrophic factors play an important role in PNS nerve regeneration $38,44,46,59,60,66-69,71,75,95$, 96,101 (as described in reviews ${ }^{21,32,34,62,64,74,91}$ ). The studies of the effectiveness of neurotrophic factors in pro- moting axon regeneration in the CNS have also relied on morphological assessment of axon growth and behavioral outcomes ${ }^{15,16,26,43,78,79,92,94,98}$ (as described in reviews $\left.{ }^{10,47,57,61,63,70,90,93}\right)$. While morphological and functional evaluations of nerve regeneration have the potential for clinical relevance, the data interpretation has been confounded by the fact the morphological evaluations do not take into account the normal outgrowth of many axonal sprouts from the nerve stump proximal to the injury in both PNS and CNS studies of axon regeneration.29,34 Counts of regenerating axons within nerve grafts or conduits do not necessarily reflect increased axon regeneration from the proximal nerve stump. The study of Aitken and colleagues ${ }^{3}$ was seminal in its findings that each proximal axon can give rise to as many as 20 axons regenerating into the distal nerve stump. Hence the ratio of the regenerating axons in the distal nerve stump and axons in the proximal nerve stump could be as high as 20:1. After target reinnervation, the ratio of regenerated axons in the distal nerve stump as compared with the axons proximal to the nerve injury and repair is 5:1.65 This ratio is progressively and slowly reduced as the supernumerary branches are withdrawn over a lengthy period of more than 2 years in rats. ${ }^{65}$ This striking emission of many regenerated axons by each neuron, the regenerating unit, is frequently referred to as sprouting from the proximal nerve stump with several axons entering into single endoneurial tubes in the distal nerve stump. Hence, morphological analysis 
A.

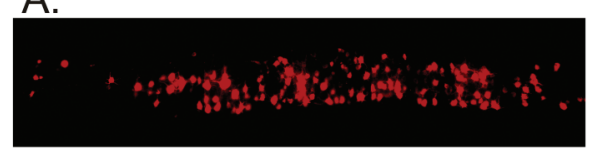

C.

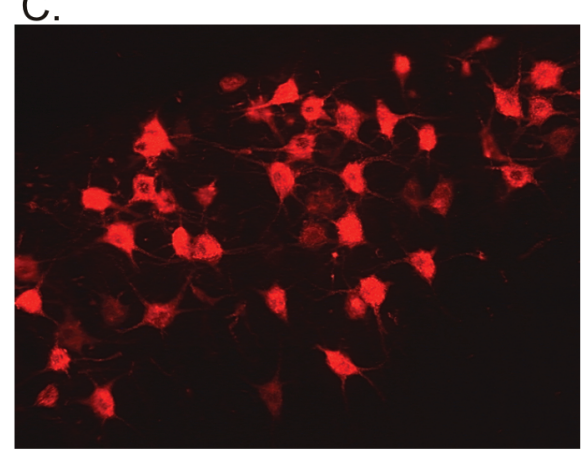

B.

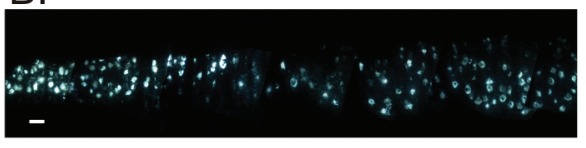

D.

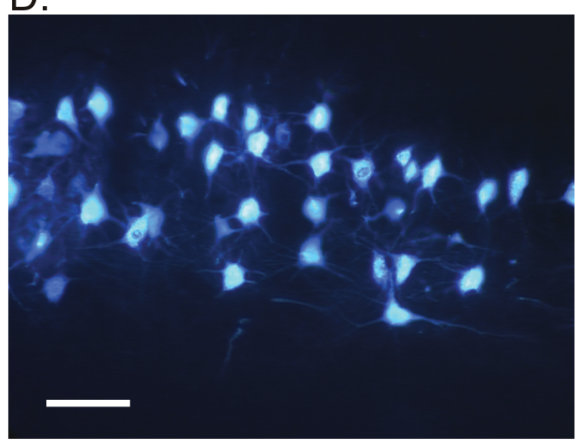

E.

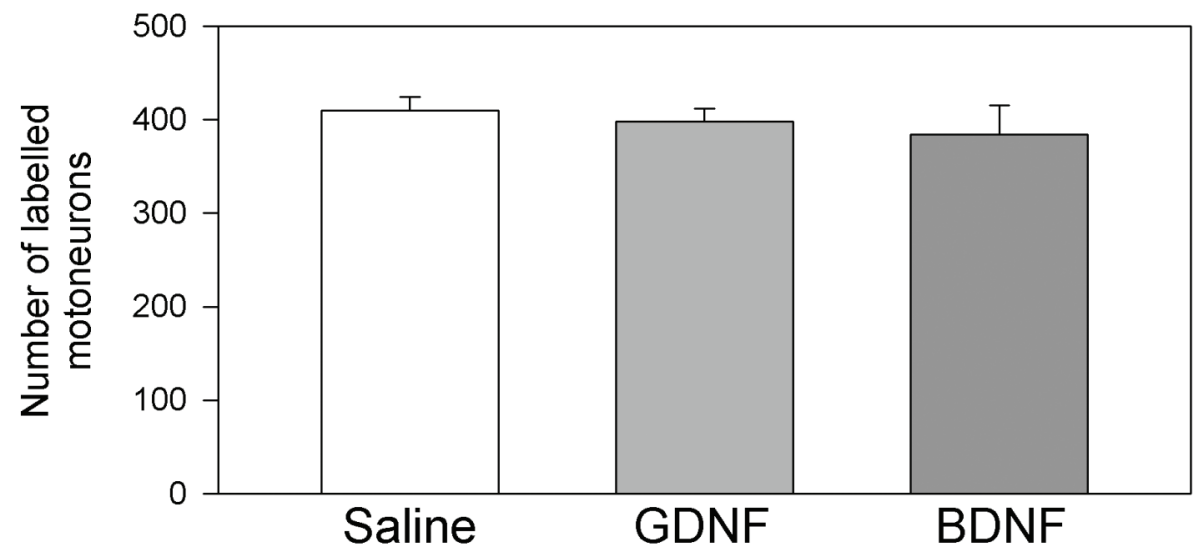

FIG. 2. Lack of effect of either BDNF or exogenous GDNF on the regenerative success of motoneurons after immediate transection and surgical reunion. A-D: Low-magnification ( $A$ and $B$ ) and high-magnification ( $C$ and $D)$ photomicrographs of representative $50-\mathrm{mm}$ longitudinal sections through the ventral horn of the T1-L1 spinal segments of tibial motoneurons labeled with fluoro-ruby (A and C) or Fluoro-Gold (B and D). E: Bar graph showing the means ( \pm standard errors of the means) of the number of dye-labeled tibial motoneurons that regenerated their axons $20 \mathrm{~mm}$ into the common peroneal distal nerve stump 28 days after immediate cross-suture of the proximal nerve stump of the transected tibial nerve and the distal nerve stump of the transected common peroneal nerve and infusion of saline, a low dose of GDNF ( $0.1 \mu \mathrm{g} /$ day), or a low dose of BDNF (2 mg/ day). The infusion was via a mini-osmotic pump to the suture site, which was encased within a 5-mm long Silastic tube. The neurotrophic factors did not significantly alter the number of tibial motoneurons that regenerated their axons after immediate nerve repair. Scale bar $=100 \mu \mathrm{m}$ (A and B). Modified from Boyd and Gordon: Exp Neurol 183:610-619, 2003, and Boyd and Gordon: Eur J Neurosci 15:613-626, 2002.

of regenerating axons cannot, without independent measures of regenerative capacity of the axotomized neurons, differentiate the process of axonal sprouting from single axons in the proximal nerve stump from the regeneration of axons from several of the proximal axons.

The potential effect of the neurotrophic factors in promoting sprouting as opposed to promoting axon regeneration can be resolved using fluorescent dyes that are transported retrogradely to the cell body in order to enumerate how many neurons regenerate their axons - an independent measure of regenerative capacity of axotomized neurons that may be combined with the morphological counts and analysis of the regenerated nerves distal to the injury site. Fluorescent retrograde and anterograde labeling of regenerating axons can resolve the process of regeneration. Fluorescent dyes such as fluoro-ruby (dextran tetramethylrhodamine, D-1817; Invitrogen), Fluoro-Gold (Fluorochrome, Inc.), or fast blue are applied to the distal nerve stump at different times after nerve injury and surgical repair. Their visualization in the neuronal cell bodies in the spinal cord and in the dorsal root ganglia permits the enumeration of the neurons that regenerate their axons. These counts can be combined with axon counts to allow determination of both regenerative success and sprouting capacity. , $, 11,12,14,17,18,22,37,39,40,42,50,84,86-89$ Visualization of regenerating axons in transgenic mice that express a visible protein such as green fluorescent protein (GFP) under a specific neuronal promoter provides a measure of the distance over which axons regenerate. . $^{23,24,45,73,95}$

In this review, the evidence for roles of neurotrophic factors in regeneration of injured PNS nerves is presented in the context of methods that provide good evidence 
A. Intact

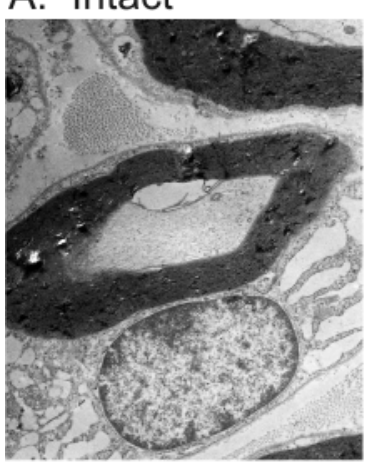

C. GDNF

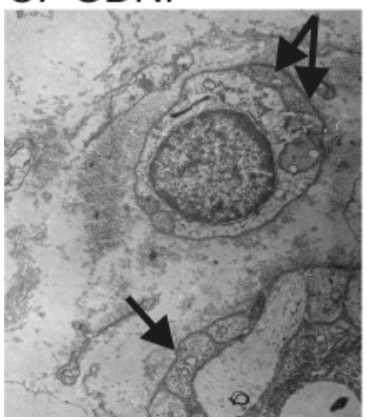

B. Saline
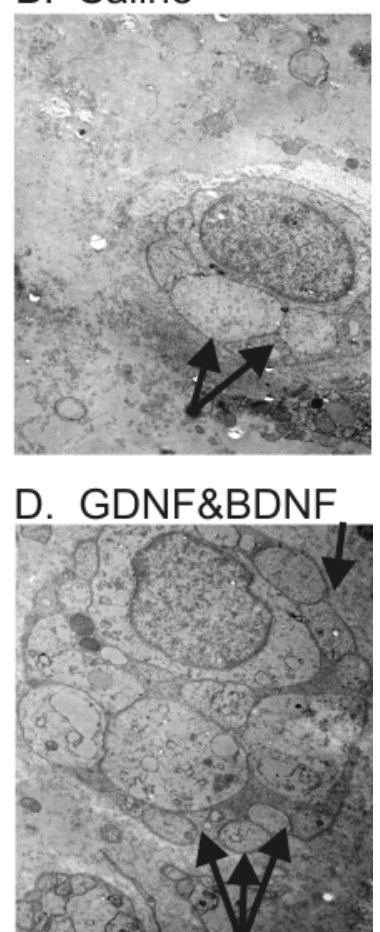

FIG. 3. Transmitting electron micrographs of Schwann cells and their axons showing the effect of the neurotrophic factors BDNF and GDNF in promoting regenerative sprouting of axons after nerve injury and surgical repair. A: A single axon is visible in association with a myelinating Schwann cell in the intact nerve. B: One month after nerve transection of the tibial nerve and surgical cross-union of tibial (proximal nerve stump) and common peroneal (distal nerve stump) nerves in Sprague-Dawley rats, typical regenerating units, consisting of a Schwann cell and several (4) daughter axons, are seen after daily saline administration via an implanted mini-osmotic pump. C: The number of axon sprouts/Schwann cells is increased following exogenous GDNF administration. D: The number of axon sprouts/Schwann cells is increased further following exogenous daily administration of both GDNF and BDNF. The arrows point to axon profiles. Modified from Boyd and Gordon: Eur J Neurosci 15:613-626, 2002

that indeed neurotrophic factors play a key role in axon regeneration in the PNS. Attention is given to providing evidence that 1) sufficient endogenous sources of neurotrophic factors are normally available to support axon regeneration, and 2) insufficient endogenous sources are available under conditions in which injured neurons regenerate their axons over long distances before the axons remake target connections with muscles and sense organs. Also described is the importance of accelerating the axon outgrowth across the surgical sites of nerve repair where the delays may require months rather than days.

Although there is now considerable evidence for key roles of neurotrophic factors in the survival and axon regeneration of injured CNS neurons, these are beyond the scope and focus of this review. The reader is referred to recent reviews. ${ }^{15,27,28,48,63,70,72}$

\section{Neurotrophic Factors and PNS Axon Regeneration}

In the PNS, retrograde labeling of regenerating axons in the distal stump of a rat hindlimb nerve 1 month after transection, immediate nerve repair, and continuous exposure to exogenous BDNF or GDNF, revealed that neither low-dose BDNF nor GDNF affected axon regeneration: the neurotrophic factors did not change the number of neurons that regenerated their axons into the distal nerve stump (Fig. 2). ${ }^{11,12}$ The profound inhibitory effects of high doses of BDNF on axon regeneration mediated via p75 receptors on neurons ${ }^{11,12,14,39,42}$ and the hypothesized role of high concentrations of BDNF in formation of target connections were recently reviewed in detail ${ }^{13,39,42,85}$ and are not considered further here. Thus, despite the several morphological studies that reported positive effects of the same neurotrophic factors on axonal regeneration after immediate nerve repair, the factors did not affect the number of neurons that regenerated their axons (Fig. 2). Importantly, examination of the number of axons in the distal nerve stump after the exogenous treatment of the cut and repaired peripheral nerves did reveal that, indeed, the neurotrophic factors, administered alone or in combination, had a profound and significant effect of increasing the number of regenerating axons that accompanied each Schwann cell in a regenerating unit (Fig. 3). ${ }^{12}$ Hence, as suspected, the neurotrophic factors did promote extensive outgrowth of axons, with electron microscopic evidence of sprouting (Fig. 3).

The finding that exogenous BDNF and GDNF promote axon sprouting but do not increase the number of neurons that regenerate their axons after nerve transection and surgical repair does not negate an influence of the neurotrophic factors on axon regeneration. Indeed, the evidence that the neurotrophic factors have a significant effect of increasing the number of neurons that regenerate their axons after prolonged axotomy, argues strongly that the factors play a central role in axon regeneration in the PNS. Endogenous neurotrophins are upregulated in neurons after axotomy and in the denervated Schwann cells in the distal stumps (Fig. 4). 1,8,13,31,32,34,35,49,56,64,67,68, $76,83,91$ The Schwann cells that myelinate motor and sensory axons show distinctive patterns of upregulation of neurotrophic factors once the axon degenerates within the distal nerve stumps after nerve injury. ${ }^{51}$ Denervated motor Schwann cells specifically upregulate BDNF and p75, whereas the sensory Schwann cells demonstrate a much broader spectrum of neurotrophin upregulation, including the expression of pleiotrophin. The latter broad spectrum of changes in the sensory Schwann cells reflects the heterogeneous population of dorsal root ganglion neurons with large-to-small diameter somas and nerve fibers that subserve different sensations of proprioception, touch, temperature, and pain..$^{98}$

After immediate repair of injured peripheral nerves where exogenous administration of neurotrophic factors does not increase the number of neurons that regenerate their axons, the regenerating axons in the distal nerve stumps have access to the neurotrophic factors that are expressed within the stumps. These are retrogradely transported to the neuronal cell bodies and together with the increased expression of the neurotrophic factors in the soma of the axotomized neurons are likely quite sufficient to support axonal regeneration. This exposure to 


\section{A. Axotomized neuron}

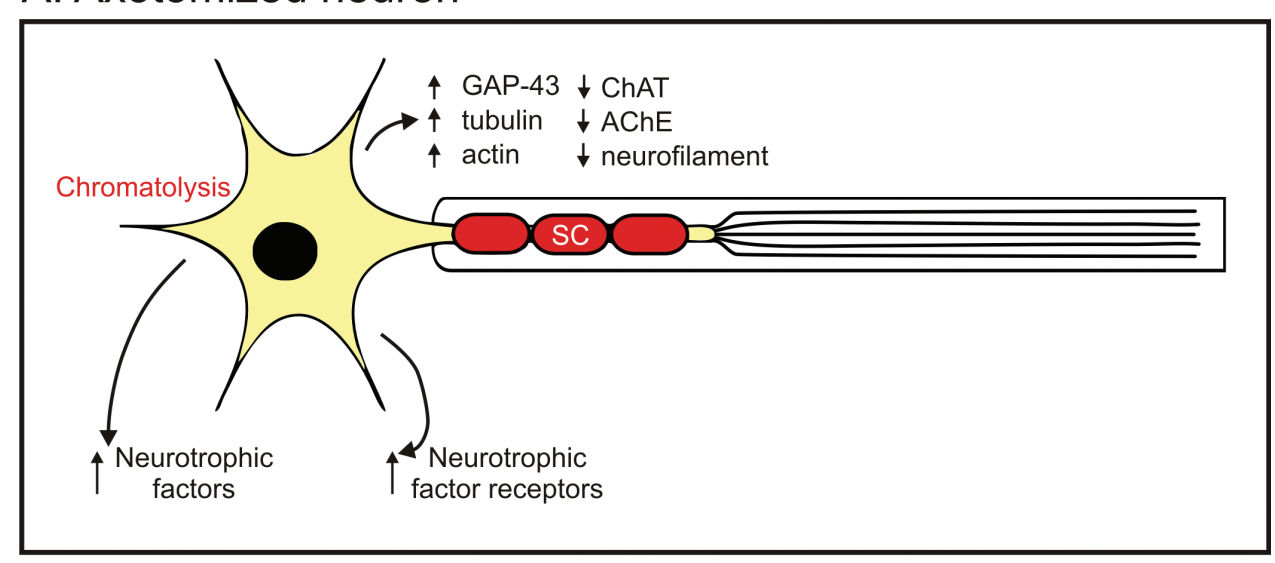

\section{B. Denervated Schwann cells}

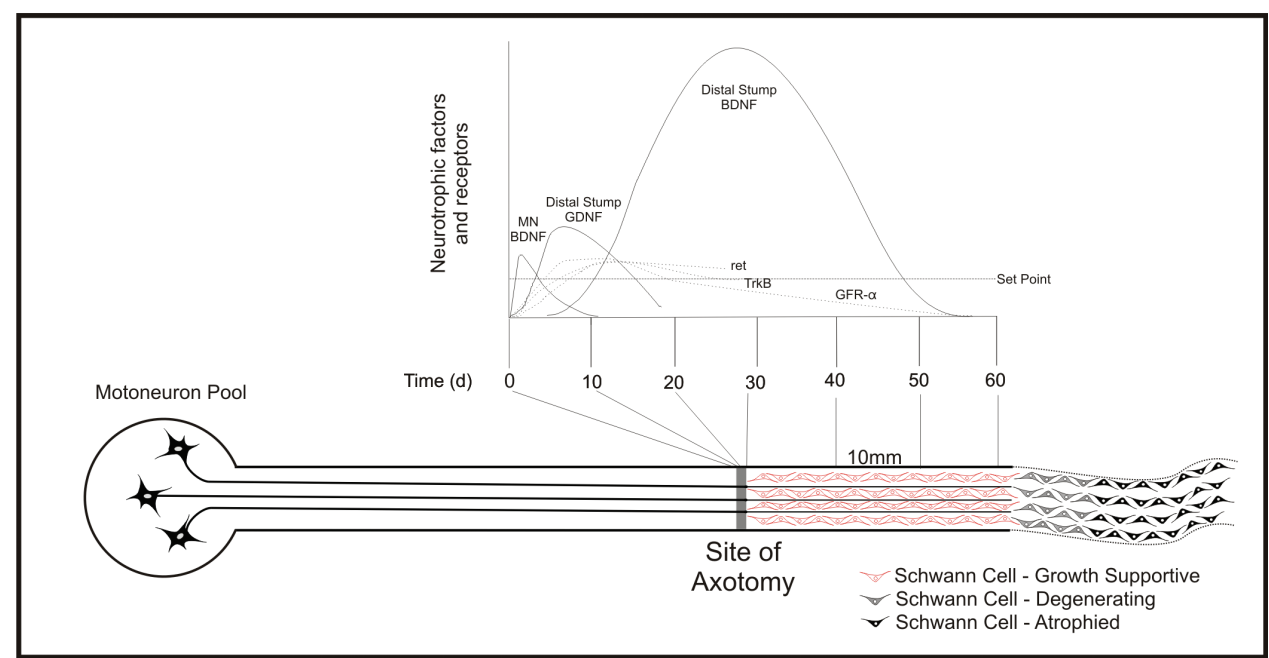

FIG. 4. Schematic illustrations of the upregulation of neurotrophic factors in axotomized neurons (A) and denervated Schwann cells (B) in the distal stump after axon transection. Neurotrophic factors are upregulated in the soma of axotomized neurons in association with upregulation of growth-associated proteins GAP-43, tubulin, and actin, and with emission of axonal sprouts from the transected proximal nerve stump; in Schwann cells of the endoneurial tubes of the nerve stumps distal to the nerve transection site, BDNF and trkB are rapidly upregulated by the motoneurons as are GDNF and its receptors, ret and FGR- $\alpha$. The neurotrophic factors are downregulated rapidly, but the expression of the receptors decline more slowly. The upregulation of the factors in the distal nerve stump is greater especially for BDNF but the up- and downregulation of BDNF occurs more gradually than in the motoneurons.

endogenous neurotrophic factors accounts for the lack of any positive effect of the exogenous administration of the factors on the number of neurons that regenerate their axons. ${ }^{11-14,42}$

After delayed nerve repair, however, when the nerves in the proximal nerve stump are prevented from regenerating their axons for long periods or the axotomized neurons regenerate their axons but are prevented from making target connections, a condition of chronic axotomy, even the neurotrophic factor production by the Schwann cells in a freshly denervated nerve stump (of another nerve) is not sufficient to support the outgrowth and regeneration of axons: the number of chronically axotomized tibial motoneurons that regenerated their axons into the freshly denervated common peroneal nerve stumps was significantly less than the number that did so after immediate nerve repair of freshly axotomized and denervated nerves (Fig. 5A). ${ }^{11,14,36,42}$ Under these conditions of chronic axotomy of the motoneurons, exogenous neurotrophic factors were effective in promoting axon regeneration-that is, more motoneurons regenerated their axons when BDNF and/or GDNF were infused continuously at the suture site over the 28-day period of axon regeneration (Fig. 5A). ${ }^{11,12}$ As shown in the histogram in Fig. 5A, neurotrophic factors were required to be administered continuously over 7 days to reverse the deleterious effect of the chronic axotomy on the regenerative potential of the tibial motoneurons and over a full 30 days to significantly elevate the regenerative potential above normal. These findings suggest that the endogenous supply of neurotrophic factors from Schwann cells and perhaps the fibroblasts in the growth pathway do indeed support regenerating axons as 

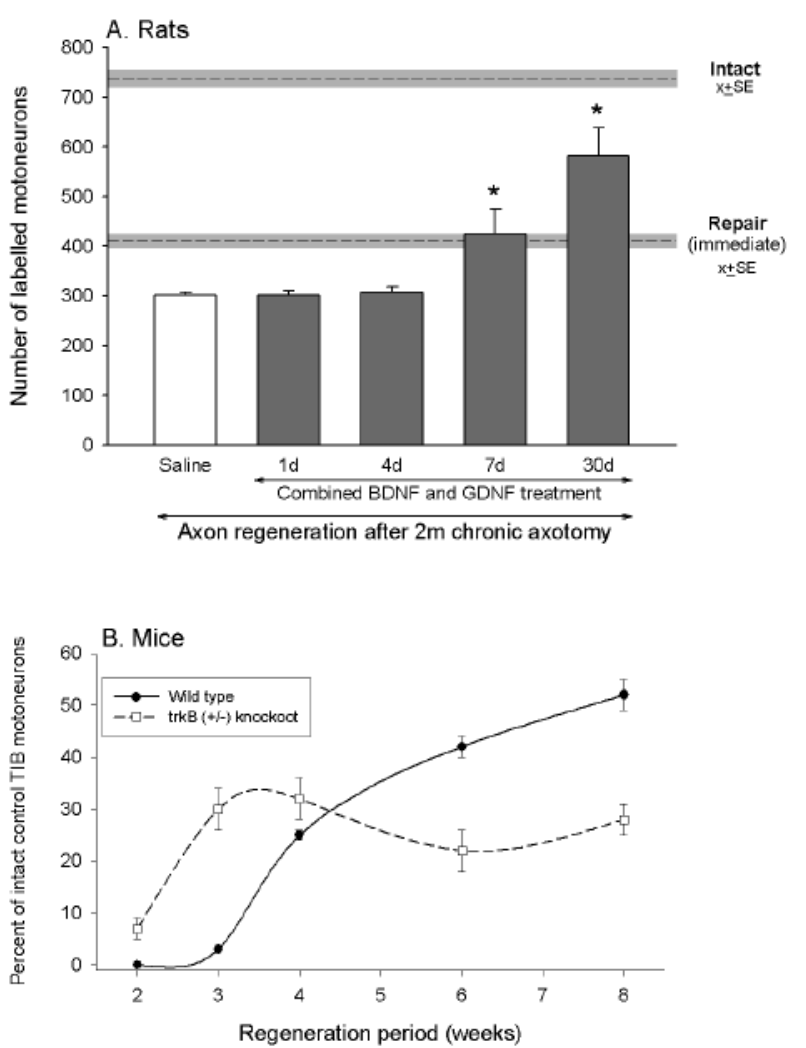

FIG. 5. Graphs showing the effects of neurotrophic factors on axon regeneration. Exogenous neurotrophic factors not only reverse the deleterious effects of chronic axotomy on regeneration of axons, but they also increase axon regeneration after nerve transection and repair. A: Thirty days after nerve transection and either immediate or delayed nerve repair in rats, regenerating axons were exposed to fluoro-ruby or to Fluoro-Gold $20 \mathrm{~mm}$ from the surgical repair site to count the number of motoneurons that regenerate their axons into the distal nerve stump. When nerve transection was followed by nerve repair 2 months later (delayed nerve repair/chronic axotomy), the number of motoneurons that regenerated their axons $20 \mathrm{~mm}$ distal to the repair site increased progressively to a significantly higher number 30 days after nerve repair. ${ }^{*} p<0.05$ for difference between the regenerating motoneurons that were treated with neurotrophic factors and the salinetreated control neurons. B: After tibial motoneurons were cut and surgically repaired in wild-type and trkB $\mathrm{B}^{ \pm}$knockout transgenic mice, a regeneration rate of $3 \mathrm{~mm} /$ day would predict that all the motoneurons in the wild-type mice would regenerate their axons over a $10-\mathrm{mm}$ distance within a week. Instead there is a prolonged period of axon regeneration with the number of motoneurons that regenerated their axons 10 $\mathrm{mm}$ distal to the repair site increasing slowly and progressively over an 8-week period. This slow regeneration process reflects the protracted or staggered axonal regeneration that occurs at the suture site. 5,17 Although there was an initial period during which enhanced numbers of motoneurons regenerated their axons in the trkB ${ }^{ \pm}$transgenic mice, significantly fewer motoneurons regenerated their axons over the 10$\mathrm{mm}$ distance 6 and 8 weeks after immediate nerve repair. Refer to the text for explanations for these results. Modified from Boyd and Gordon: J Neurobiol 49:314-325, 2001, and Boyd and Gordon: Exp Neurol 183:610-619.

they grow and elongate within the distal nerve stumps as illustrated in Fig. 4B.

Because the expression of the neurotrophic factors and their receptors declines within a week of axotomy in motoneurons and decays considerably more slowlywithin 60 days-in the distal nerve stumps, it is likely that the elevated levels of neurotrophic factors and their receptors in the distal nerve stumps play a critical role in the trophic support of axon regeneration. Especially as axon sprouts from the proximal nerve stumps "stagger" across the suture line such that all the regenerating axons cross the suture line over a 30-day period even after immediate nerve repair, the more sustained period of neurotrophic support from the distal nerve stumps is likely to be very important..$^{5,14,17,41}$ In support of this contention, the regenerative capacity of axotomized motoneurons was found to be significantly reduced in heterozygote trkB knockout transgenic mice even after immediate repair (Fig. 5B). 13,39,42 This reduction was seen 6-8 weeks after the nerve transection and surgical repair in the trkB ${ }^{+}$ knockout mice when the number of motoneurons that regenerate their axons across the injury site and into the distal nerve stump normally increases in the staggered fashion described by Al-Majed et al. ${ }^{5,14}$ Yet initially, the motor axonal regeneration in the $\operatorname{trkB}^{+}$mice is significantly improved as compared with the wild-type controls. This improved axonal regeneration during the first month of axon regeneration in the distal nerve stump is probably due to a reduction of the trkB receptors that are expressed in a truncated form on the denervated Schwann cells in the distal nerve stump. There is evidence that these truncated trkB receptors normally reduce axon outgrowth by endocytosing and thereby removing bound trkB ligands from the environment of the growing axons..$^{33}$ Reduction in the number of these trkB receptors would increase the availability of the neurotrophin ligands during the previous early phase of axon regeneration when the relatively slow synthesis and release of the neurotrophins is not yet optimum for support of axonal regeneration.

\section{Role of Neurotrophic Factors in Accelerated Axon Out- growth After Brief Electrical Stimulation}

Additional experimental support for a critical role for endogenous neurotrophins in axon regeneration in the PNS is the finding that a brief period (1 hour) of bipolar $20-\mathrm{Hz}$ electrical stimulation of a peripheral nerve proximal to the site of nerve transection and surgical repair promotes an earlier and striking upregulation of BDNF and trkB in the axotomized motoneurons. ${ }^{4}$ This accelerated neurotrophic factor upregulation also occurs in sensory neurons and correlates with striking accelerated axon outgrowth across the surgical reunion site after electrical stimulation. ${ }^{18,37}$

A short initial period of a few days is generally accepted to precede a steady rate of axonal regeneration of axons of $1-3 \mathrm{~mm} /$ day within the endoneurial tubes. ${ }^{52,53,80}$ However, the use of retrograde labeling of neurons across the surgical repair site and into distal nerve stumps has made it clear that axon regeneration across the surgical site or even though an area of axon disruption in a crush site is a slow and staggered process..$^{4,17}$ This process of staggered axon regeneration and not the rate of axonal regeneration within the distal nerve stumps is accelerated by brief electrical stimulation. ${ }^{17,18}$ Visualization of the regenerating axons in mice reveals that electrical stimula- 


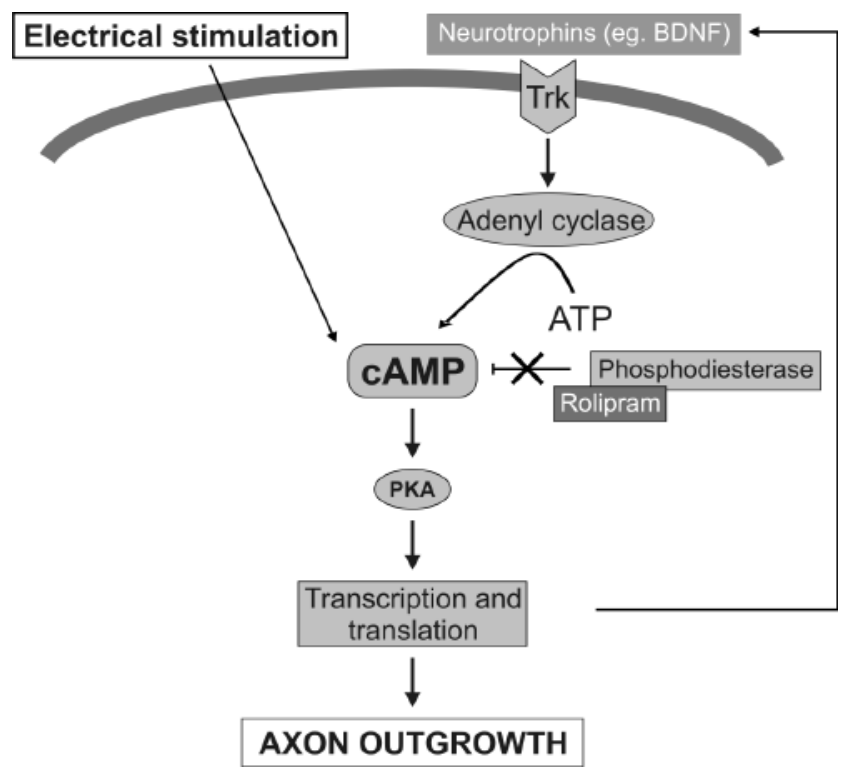

FIG. 6. Figurative representation of the role of neurotrophic factors in promoting axon outgrowth from the proximal nerve stump of axotomized neurons. Electrical stimulation that elevates intracellular cAMP levels is mimicked by blocking phosphodiesterase with rolipram. The cAMP initiates gene transcription and translation of neurotrophins and their trk receptors via PKA. The trk receptors act downstream on adenyl cyclase to sustain elevated intracellular cAMP levels and, in turn, promote expression of growth-associated genes for axon outgrowth.

tion promotes the sprouting of axons into the distal nerve stump, ${ }^{30}$ reminiscent of the effect of exogenous BDNF in the surgical site of immediate nerve repair, in promoting sprouting.In both cases, the levels of BDNF and trkB are elevated in the axotomized motoneurons, with the elevation accelerated by the electrical stimulation. ${ }^{4}$ Axons that sprout and grow across the surgical site have limited access to the proliferating Schwann cells that migrate from the distal stump. These Schwann cells upregulate neurotrophic factors relatively slowly (Fig. 4B). It is only when the Schwann cells align in the surgical gap over a period of 5 days or more, ${ }^{100}$ and neurotrophins are upregulated in the Schwann cells, that the axotomized neurons can access neurotrophic factors from these Schwann cells. Hence the neuronal source of neurotrophic factors is likely to be critical during these earlier times of axon outgrowth.

This idea is supported by the fact that electrical stimulation accelerates neuronal expression of neurotrophic factor BDNF and its receptor trkB and accelerates axon outgrowth across the surgical gap into the nerve stump. ${ }^{4,5,22,25,37}$ Knockout of NT-4/5 in neurons in transgenic mice, whose regenerating axons grow into the allografts of a distal nerve stump from normal wild type mice, significantly reduces axon elongation in the allograft and counteracts the positive effect of the 1-hour electrical stimulation in promoting elongation of the regenerating axons. ${ }^{24,25}$ In accordance with these findings, the upregulation of BDNF and trkB in the brain and spinal cord in response to exercise is likely to account for the increased length of regenerating axons that follows daily 1-hour continuous treadmill exercise over
10 days. ${ }^{81}$ Hence it is likely that upregulation of neurotrophic factors in the neurons plays a key role in axon outgrowth from axotomized neurons, with additional support being provided by Schwann cells in the growth pathways of the cell-lined endoneurial tubes in the distal nerve stump.

\section{Cyclic AMP, Neurotrophic Factor Synthesis, and Axon Regeneration}

The growth-associated genes of the cytoskeletal proteins actin and tubulin and the growth-associated protein GAP-43 are upregulated after axotomy in concert with downregulation of neurofilament protein. ${ }^{9}$ Electrical stimulation for 1 hour accelerates this upregulation such that these genes are expressed at 2 days after nerve transection, repair, and electrical stimulation at levels 3 times higher than the initial expression of the genes in sham-stimulated control nerves after the same nerve transection and surgical repair. ${ }^{6}$ The expression of the cytoskeletal proteins and GAP-43 is preceded by the pronounced upregulation of BDNF and trkB receptors in the axotomized motoneurons after nerve repair and electrical stimulation; ${ }^{4}$ this upregulation is, in turn, preceded by elevated levels of cAMP in the stimulated neurons (T. Gordon, unpublished data). This early rise in intracellular cAMP levels after electrical stimulation likely follows increased calcium entry into the neuronal cell body. This increased intracellular cAMP, when induced by administration of rolipram, a specific inhibitor of neuronal phosphodiesterase IV, also accelerates axon outgrowth after immediate nerve suture, mimicking the effect of brief low-frequency electrical stimulation. ${ }^{41}$ Indeed, pharmacological manipulation of cAMP and downstream protein kinase A (PKA) has the corresponding effects on motoneurons in vitro: elevated cAMP via PKA promotes neurite outgrowth and elongation and reduced cAMP and downstream PKA inhibition retards it. ${ }^{2}$ These findings indicate that electrical stimulation via calcium entry elevates cAMP levels and then, in turn, via PKA enhances gene expression of neurotrophins in the neurons to accelerate axon outgrowth (Fig. 6).

\section{Summary and Conclusions}

In summary, quantitative techniques have been used to enumerate the neurons that regenerate to distinguish axon regeneration from axonal sprouting that results in higher distal to proximal axon numbers. These techniques have been critical to providing a systematic evaluation of the role of neurotrophic factors derived from Schwann cells and the neurons themselves in axonal regeneration. The findings provide strong support for endogenous neurotrophic factors of axotomized neurons and of denervated Schwann cells playing a critical role in promoting axon regeneration. Indeed, as the expression of neurotrophic factors in the neurons and the Schwann cells declines with time,${ }^{50}$ there is a corresponding decline in the capacities of chronically axotomized neurons to regenerate and for chronically denervated Schwann cells to support regenerating neurons and their axons. These findings provide the basis for promoting techniques such as 
retroviral infection of neurons and their Schwann cells to sustain neurotrophic support. It must be noted, however, that levels of these factors are important because, in the case of the neurotrophic factors that mediate their effects via trk and p75 receptors, high concentrations of neurotrophic factors that mediate their effects via $\mathrm{p} 75$ rather than trk receptors, such as BDNF, inhibit axon growth and may even promote neuronal death. ${ }^{11,14,39}$ Hence, both the biological timing and the expression levels of the neurotrophic factors are critical in promoting axon regeneration.

Surgical repair of injured peripheral nerves is frequently delayed in patients who suffer nerve trauma, especially when there is extensive tissue damage or when the nature of the nerve injury must be clarified. Even after immediate nerve repair, substantial periods of time elapse between surgical repair and the expected time of arrival of regenerating axons at denervated targets. Indeed, for injuries to the brachial plexus, for example, delays of years may ensue. ${ }^{39,42,85,87}$ Under these conditions, it is likely that exogenous sources of neurotrophic factors are required for axon regeneration. In light of the capacity of brief electrical stimulation to upregulate endogenous neurotrophic factors, the possibility that the stimulation may suffice to promote axon regeneration in humans is enticing. Importantly, recent findings that 1 hour of electrical stimulation of the proximal nerve stump at the time of carpal tunnel release was sufficient to promote the regeneration and reinnervation of all axons, in contrast to little reinnervation without the stimulation, indicate that, indeed, the stimulation may be sufficient to accelerate axon regeneration in human patients with nerve injuries and surgical repair. ${ }^{41}$

Pharmacological elevation of cAMP levels is sufficient to overcome the inhibitory environment of the myelin in the CNS and to thereby promote axon regeneration..$^{15,16}$ Elevation of cAMP in vitro promotes neurite outgrowth on CNS myelin; and in the CNS in vivo, rolipram is effective in elevating cAMP levels sufficiently to enhance regeneration. It is likely, however, that the coordination of neurotrophic factor expression and elevation of cAMP levels is even more critical in the CNS for promotion of axon regeneration.

\section{Disclaimer}

The author reports no conflict of interest concerning the materials or methods used in this study or the findings specified in this paper.

\section{Acknowledgments}

This work was supported by operating grants to the author from the Canadian Institutes of Health Research, including a group grant with Drs. Zochodne, Sayed, Midha, Verge, and Chan. The author is an Alberta Heritage Foundation for Medical Research senior investigator and would like to thank the many collaborators who were involved in the research in her laboratory.

\section{References}

1. Acheson A, Barker PA, Alderson RF, et al: Detection of brain-derived neurotrophic factor-like activity in fibroblasts and Schwann cells: inhibition by antibodies to NGF. Neuron 7:265-275, 1991

2. Aglah C, Gordon T, Posse De Chaves EI: cAMP promotes neurite outgrowth and extension through protein kinase A but independently of Erk activation in cultured rat motoneurons. Neuropharmacology 55:8-17, 2008

3. Aitken JT, Sharman M, Young JZ: Maturation of peripheral nerve fibres with various peripheral connections. J Anat 81:1-22, 1947

4. Al-Majed AA, Brushart TM, Gordon T: Electrical stimulation accelerates and increases expression of BDNF and trkB mRNA in regenerating rat femoral motoneurons. Eur J Neurosci 12:4381-4390, 2000

5. Al-Majed AA, Neumann CM, Brushart TM, et al: Brief electrical stimulation promotes the speed and accuracy of motor axonal regeneration. J Neurosci 20:2602-2608, 2000

6. Al-Majed AA, Tam SL, Gordon T: Electrical stimulation accelerates and enhances expression of regeneration-associated genes in regenerating rat femoral motoneurons. Cell Mol Neurobiol 24:379-402, 2004

7. Allen SJ, Dawbarn D: Clinical relevance of the neurotrophins and their receptors. Clin Sci (Lond) 110:175-191, 2006

8. Anand P, Terenghi G, Birch R, et al: Endogenous NGF and CNTF levels in human peripheral nerve injury. Neuroreport 8:1935-1938, 1997

9. Bisby MA, Tetzlaff W: Changes in cytoskeletal protein synthesis following axon injury and during axon regeneration. Mol Neurobiol 6:107-123, 1992

10. Blottner D, Baumgarten HG: Neurotrophy and regeneration in vivo. Acta Anat (Basel) 150:235-245, 1994

11. Boyd JG, Gordon T: A dose-dependent facilitation and inhibition of peripheral nerve regeneration by brain-derived neurotrophic factor. Eur J Neurosci 15:613-626, 2002

12. Boyd JG, Gordon T: Glial cell line-derived neurotrophic factor and brain-derived neurotrophic factor sustain the axonal regeneration of chronically axotomized motoneurons in vivo. Exp Neurol 183:610-619, 2003

13. Boyd JG, Gordon T: Neurotrophic factors and their receptors in axonal regeneration and functional recovery after peripheral nerve injury. Mol Neurobiol 27:277-324, 2003

14. Boyd JG, Gordon T: The neurotrophin receptors, trkB and $\mathrm{p} 75$, differentially regulate motor axonal regeneration. J Neurobiol 49:314-325, 2001

15. Bregman BS, Coumans JV, Dai HN, et al: Transplants and neurotrophic factors increase regeneration and recovery of function after spinal cord injury. Prog Brain Res 137:257273, 2002

16. Bregman BS, McAtee M, Dai HN, et al: Neurotrophic factors increase axonal growth after spinal cord injury and transplantation in the adult rat. Exp Neurol 148:475-494, 1997

17. Brushart TM, Hoffman PN, Royall RM, et al: Electrical stimulation promotes motoneuron regeneration without increasing its speed or conditioning the neuron. J Neurosci 22:66316638, 2002

18. Brushart TM, Jari R, Verge V, et al: Electrical stimulation restores the specificity of sensory axon regeneration. Exp Neurol 194:221-229, 2005

19. Chao MV: Neurotrophins and their receptors: a convergence point for many signalling pathways. Nat Rev Neurosci 4:299-309, 2003

20. Chao MV, Rajagopal R, Lee FS: Neurotrophin signalling in health and disease. Clin Sci (Lond) 110:167-173, 2006

21. Chen ZL, Yu WM, Strickland S: Peripheral regeneration. Annu Rev Neurosci 30:209-233, 2007

22. Eberhardt KA, Irintchev A, Al-Majed AA, et al: BDNF/TrkB signaling regulates HNK-1 carbohydrate expression in regenerating motor nerves and promotes functional recovery after peripheral nerve repair. Exp Neurol 198:500-510, 2006

23. English AW: Enhancing axon regeneration in peripheral 
nerves also increases functionally inappropriate reinnervation of targets. J Comp Neurol 490:427-441, 2005

24. English AW, Meador W, Carrasco DI: Neurotrophin- $4 / 5$ is required for the early growth of regenerating axons in peripheral nerves. Eur J Neurosci 21:2624-2634, 2005

25. English AW, Schwartz G, Meador W, et al: Electrical stimulation promotes peripheral axon regeneration by enhanced neuronal neurotrophin signaling. Dev Neurobiol 67:158-172, 2007

26. Fawcett JP, Bamji SX, Causing CG, et al: Functional evidence that BDNF is an anterograde neuronal trophic factor in the CNS. J Neurosci 18:2808-2821, 1998

27. Fenrich K, Gordon T: Canadian Association of Neuroscience review: axonal regeneration in the peripheral and central nervous systems-current issues and advances. Can J Neurol Sci 31:142-156, 2004

28. Fitch MT, Silver J: CNS injury, glial scars, and inflammation: inhibitory extracellular matrices and regeneration failure. Exp Neurol 209:294-301, 2008

29. Fouad K, Pearson K: Restoring walking after spinal cord injury. Prog Neurobiol 73:107-126, 2004

30. Franz CK, Rutishauser U, Rafuse VF: Intrinsic neuronal properties control selective targeting of regenerating motoneurons. Brain 131:1492-1505, 2008

31. Friedman HCH, Aguayo AJ, Bray GM: Trophic factors in neuron-Schwann cell interactions. Ann N Y Acad Sci 883:427438, 1999

32. Frostick SP, Yin Q, Kemp GJ: Schwann cells, neurotrophic factors, and peripheral nerve regeneration. Microsurgery 18:397-405, 1998

33. Fryer RH, Kaplan DR, Kromer LF: Truncated trkB receptors on nonneuronal cells inhibit BDNF-induced neurite outgrowth in vitro. Exp Neurol 148:616-627, 1997

34. Fu SY, Gordon T: The cellular and molecular basis of peripheral nerve regeneration. Mol Neurobiol 14:67-116, 1997

35. Funakoshi H, Frisen J, Barbany G, et al: Differential expression of mRNAs for neurotrophins and their receptors after axotomy of the sciatic nerve. J Cell Biol 123:455-465, 1993

36. Furey MJ, Midha R, Xu QG, et al: Prolonged target deprivation reduces the capacity of injured motoneurons to regenerate. Neurosurgery 60:723-732, 2007

37. Geremia NM, Gordon T, Brushart TM, et al: Electrical stimulation promotes sensory neuron regeneration and growth-associated gene expression. Exp Neurol 205:347-359, 2007

38. Glazner GW, Morrison AE, Ishii DN: Elevated insulin-like growth factor (IGF) gene expression in sciatic nerves during IGF-supported nerve regeneration. Brain Res Mol Brain Res 25:265-272, 1994

39. Gordon T, Boyd JG, Sulaiman OAR: Experimental approaches to promote functional recovery after severe peripheral nerve injuries. Eur Surg 37:193-203, 2005

40. Gordon T, Brushart TM, Amirjani N, Chan KM: The potential of electrical stimulation to promote functional recovery after peripheral nerve injury-comparisons between rats and humans. Acta Neurochir Suppl 100:3-11, 2007

41. Gordon T, Chan KM, Sulaiman OAR, et al: Accelerating axon growth to overcome limitations in functional recovery after peripheral nerve injury. Neurosurgery [in press], 2009

42. Gordon T, Sulaiman OAR, Boyd JG: Experimental strategies to promote functional recovery after peripheral nerve injuries. J Peripher Nerv Syst 8:236-250, 2003

43. Grill RJ, Blesch A, Tuszynski MH: Robust growth of chronically injured spinal cord axons induced by grafts of genetically modified NGF-secreting cells. Exp Neurol 148:444-452, 1997

44. Grothe C, Nikkhah G: The role of basic fibroblast growth factor in peripheral nerve regeneration. Anat Embryol (Berl) 204:171-177, 2001

45. Groves ML, McKeon R, Werner E, et al: Axon regeneration in peripheral nerves is enhanced by proteoglycan degradation. Exp Neurol 195:278-292, 2005

46. Guntinas-Lichius O, Irintchev A, Streppel M, et al: Factors limiting motor recovery after facial nerve transection in the rat: combined structural and functional analyses. Eur J Neurosci 21:391-402, 2005

47. Gurgo RD, Bedi KS, Nurcombe V: Current concepts in central nervous system regeneration. J Clin Neurosci 9:613-617, 2002

48. Hannila SS, Filbin MT: The role of cyclic AMP signaling in promoting axonal regeneration after spinal cord injury. Exp Neurol 209:321-332, 2008

49. Henderson CE, Phillips HS, Pollock RA, et al: GDNF: a potent survival factor for motoneurons present in peripheral nerve and muscle. Science 266:1062-1064, 1994

50. Hoke A, Gordon T, Zochodne DW, et al: A decline in glial cell-line-derived neurotrophic factor expression is associated with impaired regeneration after long-term Schwann cell denervation. Exp Neurol 173:77-85, 2002

51. Hoke A, Redett R, Hameed H, et al: Schwann cells express motor and sensory phenotypes that regulate axon regeneration. J Neurosci 26:9646-9655, 2006

52. Holmquist B, Kanje M, Kerns JM, et al: A mathematical model for regeneration rate and initial delay following surgical repair of peripheral nerves. J Neurosci Methods 48:27-33, 1993

53. Kanje M, Lundborg G, Edstrom A: A new method for studies of the effects of locally applied drugs on peripheral nerve regeneration in vivo. Brain Res 439:116-121, 1988

54. Kaplan DR, Miller FD: Neurotrophin signal transduction in the nervous system. Curr Opin Neurobiol 10:381-391, 2000

55. Kaplan DR, Miller FD: Signal transduction by the neurotrophin receptors. Curr Opin Cell Biol 9:213-221, 1997

56. Kobayashi NR, Bedard AM, Hincke MT, et al: Increased expression of BDNF and trkB mRNA in rat facial motoneurons after axotomy. Eur J Neurosci 8:1018-1029, 1996

57. Kuffler D: Can regeneration be promoted within the spinal cord? P R Health Sci J 19:241-252, 2000

58. Levi-Montalcini R, Calissano P: The nerve-growth factor. Sci Am 240:68-77, 1979

59. Lewin SL, Utley DS, Cheng ET, et al: Simultaneous treatment with BDNF and CNTF after peripheral nerve transection and repair enhances rate of functional recovery compared with BDNF treatment alone. Laryngoscope 107:992-999, 1997

60. Li ST, Archibald SJ, Krarup C, et al: Peripheral nerve repair with collagen conduits. Clin Mater 9:195-200, 1992

61. Lindsay RM, Wiegand SJ, Altar CA, et al: Neurotrophic factors: from molecule to man. Trends Neurosci 17:182-190, 1994

62. Liuzzi FJ, Tedeschi B: Peripheral nerve regeneration. Neurosurg Clin N Am 2:31-42, 1991

63. Lu P, Tuszynski MH: Growth factors and combinatorial therapies for CNS regeneration. Exp Neurol 209:313-320, 2008

64. Lundborg G, Dahlin L, Danielsen N, et al: Trophism, tropism, and specificity in nerve regeneration. J Reconstr Microsurg 10:345-354, 1994

65. Mackinnon SE, Dellon AL, O'Brien JP: Changes in nerve fiber numbers distal to a nerve repair in the rat sciatic nerve model. Muscle Nerve 14:1116-1122, 1991

66. Mahay D, Terenghi G, Shawcross SG: Schwann cell mediated trophic effects by differentiated mesenchymal stem cells. Exp Cell Res 314:2692-2701, 2008

67. Meyer M, Matsuoka I, Wetmore C, et al: Enhanced synthesis of brain-derived neurotrophic factor in the lesioned peripheral nerve: different mechanisms are responsible for the regulation of BDNF and NGF mRNA. J Cell Biol 119:45-54, 1992

68. Mi R, Chen W, Hoke A: Pleiotrophin is a neurotrophic factor for spinal motor neurons. Proc Natl Acad Sci U S A 104:4664-4669, 2007

69. Midha R, Munro CA, Dalton PD, et al: Growth factor en- 
hancement of peripheral nerve regeneration through a novel synthetic hydrogel tube. J Neurosurg 99:555-565, 2003

70. Mocchetti I, Wrathall JR: Neurotrophic factors in central nervous system trauma. J Neurotrauma 12:853-870, 1995

71. Moir MS, Wang MZ, To M, et al: Delayed repair of transected nerves: effect of brain-derived neurotrophic factor. Arch Otolaryngol Head Neck Surg 126:501-505, 2000

72. Moon L, Bunge MB: From animal models to humans: strategies for promoting CNS axon regeneration and recovery of limb function after spinal cord injury. J Neurol Phys Ther 29:55-69, 2005

73. Myckatyn TM, Mackinnon SE, Hunter DA, et al: A novel model for the study of peripheral-nerve regeneration following common nerve injury paradigms. J Reconstr Microsurg 20:533-544, 2004

74. Navarro X, Vivo M, Valero-Cabre A: Neural plasticity after peripheral nerve injury and regeneration. Prog Neurobiol 82:163-201, 2007

75. Novikov L, Novikova L, Kellerth JO: Brain-derived neurotrophic factor promotes axonal regeneration and long-term survival of adult rat spinal motoneurons in vivo. Neuroscience 79:765-774, 1997

76. Peng HB, Yang JF, Dai Z, et al: Differential effects of neurotrophins and schwann cell-derived signals on neuronal survival/growth and synaptogenesis. J Neurosci 23:5050-5060, 2003

77. Pezet S, McMahon SB: Neurotrophins: mediators and modulators of pain. Annu Rev Neurosci 29:507-538, 2006

78. Plunet W, Kwon BK, Tetzlaff W: Promoting axonal regeneration in the central nervous system by enhancing the cell body response to axotomy. J Neurosci Res 68:1-6, 2002

79. Priestley JV, Ramer MS, King VR, et al: Stimulating regeneration in the damaged spinal cord. J Physiol (Paris) 96:123133,2002

80. Rusovan A, Kanje M: Stimulation of regeneration of the rat sciatic nerve by $50 \mathrm{~Hz}$ sinusoidal magnetic fields. Exp Neurol 112:312-316, 1991

81. Sabatier MJ, Redmon N, Schwartz G, et al: Treadmill training promotes axon regeneration in injured peripheral nerves. Exp Neurol 211:489-493, 2008

82. Sendtner M, Holtmann B, Kolbeck R, et al: Brain-derived neurotrophic factor prevents the death of motoneurons in newborn rats after nerve section. Nature 360:757-759, 1992

83. Sendtner M, Stockli KA, Thoenen H: Synthesis and localization of ciliary neurotrophic factor in the sciatic nerve of the adult rat after lesion and during regeneration. J Cell Biol 118:139-148, 1992

84. Smits E, Rose PK, Gordon T, et al: Organization of single motor units in feline sartorius. J Neurophysiol 72:1885-1896, 1994

85. Sulaiman OA, Boyd JG, Gordon T: Axonal regeneration in the peripheral system of mammals, in Kettenmann H, Ransom BR (eds): Neuroglia. Oxford: Oxford University Press, 2005, pp 454-466

86. Sulaiman OA, Gordon T: Effects of short- and long-term Schwann cell denervation on peripheral nerve regeneration, myelination, and size. Glia 32:234-246, 2000
87. Sulaiman OA, Gordon T: Role of chronic Schwann cell denervation in poor functional recovery after peripheral nerve injuries and strategies to combat it. Neurosurgery [in press], 2009

88. Sulaiman OA, Midha R, Gordon T: Pathophysiology of surgical nerve disorders, in Youmans Textbook of Neurological Surgery, [in press], 2009

89. Sulaiman OA, Midha R, Munro CA, et al: Chronic Schwann cell denervation and the presence of a sensory nerve reduce motor axonal regeneration. Exp Neurol 176:342-354, 2002

90. Teng FY, Tang BL: Axonal regeneration in adult CNS neuronssignaling molecules and pathways. J Neurochem 96:15011508, 2006

91. Terenghi G: Peripheral nerve regeneration and neurotrophic factors. J Anat 194:1-14, 1999

92. Thoenen H, Hughes RA, Sendtner M: Towards a comprehensive understanding of the trophic support of motoneurons. C R Acad Sci III 316: 1158-1163, 1993

93. Thoenen H, Sendtner M: Neurotrophins: from enthusiastic expectations through sobering experiences to rational therapeutic approaches. Nat Neurosci 5 (Suppl):1046-1050, 2002

94. Tuszynski MH, Weidner N, McCormack M, et al: Grafts of genetically modified Schwann cells to the spinal cord: survival, axon growth, and myelination. Cell Transplant 7:187-196, 1998

95. Utley DS, Lewin SL, Cheng ET, et al: Brain-derived neurotrophic factor and collagen tubulization enhance functional recovery after peripheral nerve transection and repair. Arch Otolaryngol Head Neck Surg 122:407-413, 1996

96. Valero-Cabre A, Navarro X: Functional impact of axonal misdirection after peripheral nerve injuries followed by graft or tube repair. J Neurotrauma 19:1475-1485, 2002

97. Vejsada R, Tseng JL, Lindsay RM, et al: Synergistic but transient rescue effects of BDNF and GDNF on axotomized neonatal motoneurons. Neuroscience 84:129-139, 1998

98. Verge VM, Gratto KA, Karchewski LA, et al: Neurotrophins and nerve injury in the adult. Philos Trans R Soc Lond B Biol Sci 351:423-430, 1996

99. Weidner N, Blesch A, Grill RJ, et al: Nerve growth factor-hypersecreting Schwann cell grafts augment and guide spinal cord axonal growth and remyelinate central nervous system axons in a phenotypically appropriate manner that correlates with expression of L1. J Comp Neurol 413:495-506, 1999

100. Witzel C, Rohde C, Brushart TM: Pathway sampling by regenerating peripheral axons. J Comp Neurol 485:183-190, 2005

101. Yin Q, Kemp GJ, Frostick SP: Neurotrophins, neurones and peripheral nerve regeneration. J Hand Surg [Br] 23:433-437, 1998

Manuscript submitted October 16, 2008.

Accepted November 21, 2008

Address correspondence to: Tessa Gordon, Ph.D., Division of Physical Medicine and Rehabilitation, Centre for Neuroscience, 525 Heritage Medical Research Centre, Faculty of Medicine, University of Alberta, Edmonton, Alberta, Canada T6G 2S2. email: tessa. gordon@ualberta.ca. 